\title{
Seizure Impact on the School Attendance in Children with Epilepsy: Prospective Study in the Pediatrics Neurology Clinic at Tikur Anbessa Specialized Hospital,Addis Ababa, Ethiopia
}

Oumer Hassen ( $\nabla$ oumerhh@gmail.com )

Haramaya University College of Health and Medical Sciences https://orcid.org/0000-0003-3560-5117

Ayalew moges Beyene

Addis Ababa University School of Medicine

Research article

Keywords: Epilepsy; School; Childhood; Absenteeism; Ethiopia

Posted Date: October 11th, 2019

DOI: https://doi.org/10.21203/rs.2.11162/v2

License: (c) (1) This work is licensed under a Creative Commons Attribution 4.0 International License.

Read Full License

Version of Record: A version of this preprint was published at BMC Pediatrics on June 3rd, 2020. See the published version at https://doi.org/10.1186/s12887-020-02149-y. 


\section{Abstract}

Abstract Background: Epilepsy is the most common chronic neurological disease seen in Pediatrics Neurology Units in developing countries and like other chronic disorders it has been found to negatively affect school attendance and academic performance influencing school life of children. An educational underachievement can also be due to comorbid learning and behavioral problems in these children. The impact of epilepsy on school attendance may also contribute to the academic difficulties of children with epilepsy. The purpose of this study is to assess school absenteeism and determine which factors influence school absenteeism in school aged children and adolescents with epilepsy. Methods: A hospital based prospective study was conducted among school aged children and adolescents with epilepsy between the ages of 7-18 years attending at the Paediatric Neurology Clinic and their primary caretakers. A sample of 183 children and adolescents were included in the study. The participants (children and their parents/caregivers) gave information concerning the socio-demographic data, primary caregiver's information like educational status, information concerning child's seizure and epilepsy status disclosures to teachers and peer. And medical cards were thoroughly reviewed. Descriptive statistics and bi-variate logistic regression analysis was done to assess determinants of school absenteeism. Results: The prevalence of school absenteeism among children aged 7-18years at PNC follow up was 69.4\%.Among other factors female sex with AOR 2.19(95\% Cl 1.03-4.84), having symptomatic seizure AOR 2.51(95\% Cl 1.09-5.86), having seizure at school and having longer duration of seizure were statistically significant association with school absenteeism. Conclusion: This study demonstrated the school absenteeism is very common among children aged 7-18 years at PNC follow up (69.4\%) and that seizure has a significant impact on children's school attendance. Keywords: Epilepsy; School; Childhood; Absenteeism; Ethiopia Trial registration: N/A

\section{Background}

A seizure is a transient occurrence of signs and/or symptoms resulting from abnormal excessive or synchronous neuronal activity in the brain.(1) Epilepsy is a disorder of the brain characterized by an enduring predisposition to generate seizures and by the neurobiological, cognitive, psychological, and social consequences of this condition and clinical diagnosis of epilepsy usually requires the occurrence of at least 1 unprovoked epileptic seizure with either a second such seizure or enough EEG and clinical information to convincingly demonstrate an enduring predisposition to develop recurrences. For epidemiologic and commonly for clinical purposes, epilepsy is considered to be present when 2 or more unprovoked seizures occur in a time frame of longer than $24 \mathrm{hr}$.(1)

Epilepsy is the most common chronic neurological disease seen in Pediatrics Neurology Units in developing countries(2) and has prevalence of 5-10/1000 in developing countries.(3) In another study aimed to describe the patterns of neurologic morbidities among patients attending the pediatric neurology clinic of TASH in 2013 seizure disorders (both idiopathic and secondary) alone or as comorbidity, were found in $45.6 \%$ of all cases (104 of 228 cases) among which $28.8 \%$ (30 of 104) were 
idiopathic and $71.2 \%$ (74 of 104) were secondary to other disorders which shows that nearly half of the children at follow up in pediatric neurology clinic have seizure disorders. (4)

Epilepsy, like other chronic disorders such as sickle cell disease, diabetes mellitus and bronchial asthma has been found to negatively affect school attendance and academic performance.(5) While academic under-achievement and poor school attendance in children with other chronic conditions are due to recurrent morbidity, the effect of epilepsy is thought to be due to relatively reduced intelligence, psychosocial problem, anti-epileptic medication and the influence of seizure variables such as seizure type, age at onset, EEG findings and seizure control.(6) However, there is a controversy regarding the relative importance of these factors. $(7,8)$

Children with epilepsy are prone to educational underachievement as a result of co-morbid learning and behavioral problems. Other factors that may contribute to poor school performance amongst epilepsy patients may include overprotective parental attitudes, a lack of academic motivation, and low selfesteem. The impact of epilepsy on school attendance may also contribute to the academic difficulties of children with epilepsy.

Although most studies addressing academic performance in school-aged children with epilepsy are focused on academic achievement and quality of life of children with epilepsy, there were only few on the impact of seizure on school attendance. However, the prospective study in Brazil which was conducted at the University of Campinas, in the pediatric epilepsy clinic, from January 2005 to August 2006 which enrolled only 50 children diagnosed with epilepsy addressed this topic. The study showed $88 \%$ of patients in the study missed at least one day of school due to seizures. And almost half of the parents $(46 \%)$ believed that if the child had a seizure at school he/she should leave school immediately.(9)

According to Fernandes (2005), different variables may be related to the appearance of these problems, such as the type of epilepsy and its severity, age of the onset of crisis, but also the vision and beliefs of the general population including parents, teachers, school friends, who believe that children epileptics present more behavioral problems even when have educational repertoire and intelligence similar to those of other children healthy. Some authors point out that cognitive and social presented by children with epilepsy are not only related to intellectual deficit, but also with the possibility of the presence of stigma. (10)

It is hoped that the findings from this study will aid in formulating a suitable educational program for these children and can help teachers understand how to the best support, accommodate, and prepare for these children in their classes. And the study also contributes to the existing literature by filling gaps seen in the paucity of research on a topic from developing word.

This study will determine the impact of epilepsy on children school attendance and find out possible reasons of absenteeism from school among children with epilepsy. The result of the study will be used to show the magnitude of the impact of epilepsy on school attendance which is one of factor which 
determines the overall school performance. It will also be used literature data source for further study on the related topics.

\section{Objectives}

\subsection{General Objective}

- To assess the impact of seizure on school absenteeism and associated factors among childhood epilepsy in school age children and adolescents between the ages of 7 and 18 years who are attending follow up at the Pediatric neurology clinic in Tikur Anbessa Specialized Hospital (TASH).

\subsection{Specific Objectives}

- To describe the impact of seizure on school attendance in children with epilepsy

- To identify factors associated school attendance in children with epilepsy

\section{Literature Review}

In one study at Brazil fifty patients were evaluated, 34 boys and 16 girls; age ranged from 6 to 18 years old). Eighty-eight percent of patients in the study missed at least 1 day of school due to seizures and the same study shows the reason given by parents for a school absence was seizure in $75 \%$.(16)

Academic achievement can also be significantly impacted by many aspects of epilepsy including seizure activity, coexisting cognitive deficits, side effects of antiepileptic drugs, absenteeism, peer acceptance, and teacher understanding and expectations $(17,18)$

The literature indicates that children with epilepsy have increased rates of school absenteeism.(19) But there were few studies on the factors associated with absenteeism and there are no data about the impact of seizure on school performance internationally.

It is unclear whether some conditions may predispose a child to particularly high rates of school absence. It is also unknown whether demographic factors associated with school absenteeism in general school populations (such as socioeconomic status, maternal education, and maternal disability days) correlate with school functioning among children with epilepsy.

An epidemiological investigation conducted at community-based level which was performed in a random sample of villages with 61,686 inhabitants in a rural area of central Ethiopia showed one-hundred thirtynine incident cases were identified, corresponding to an annual incidence of 64 in 100,000 inhabitants [95\% confidence interval (Cl) 44-84] corresponding rate for males was 72 (Cl 42-102); for females, it was 57 ( $\mathrm{Cl} 31-84)$. The highest age-specific incidence occurred in the youngest age groups (0-9 years); the next highest was in the group aged 10-19 years.(9)

A 2015 CDC study, based on 2009-2010 national data, found that $36 \%$ of students aged 6 to 17 years with epilepsy were more likely to have missed 11 or more days of school in the past year, compared with 
$18 \%$ of students with other health concerns. Students with epilepsy were also more likely to have difficulties in school (such as problems communicating), use special education services, and have activity limitations (such as less participation in sports or clubs) compared with students with other medical conditions, such as autism or intellectual disability.(20)

In study with objective to compare functional difficulties and school limitations of a national sample of US children with special health care needs (CSHCN) with and without epilepsy. Among CSHCN with comorbid conditions, $36 \%$ of children with epilepsy missed 11 or more days in the past 12 months compared to $18 \%$ of children without epilepsy ( $p<0.001$ ). Among, CSHCN without comorbid conditions, there was a similar pattern. A higher percentage of children with epilepsy, compared to children without epilepsy missed 11 or more days of school (21\% vs. $15 \%$ ) and $35 \%$ of children with epilepsy, compared to $25 \%$ of children without epilepsy, were reported to have a health condition that interfered with the child's ability to participate in sports and clubs $(p<0.01)$. $(21)$

In recent study done in Sierra Leone to assess the impacts of epilepsy on child education in Sierra Leone $(\mathrm{SL})$, they carried out a cross-sectional descriptive study examining its effects on school attendance, participation in physical activities, and social acceptance among classmates. The data were collected at various epilepsy clinics and school in Freetown, SL. In which a total of 50 patients were interviewed and questionnaires administered to their caregivers and teachers, making a total of 150 respondents. Fiftyone percent of the children were absent from school for $>5$ days per month and the commonest reason being fear of occurrence of seizures. In same study regarding the caregivers about forty-eight percent were apprehensive about sending their children to school, with $83 \%$ of these caregivers stating fear of seizures and potential injuries. Only $8 \%$ of the caregivers did not prevent their children from taking part in any physical activity at school. Totally, $20 \%$ of the children ceased attending school permanently; daily occurrence of seizures $(p<0.05)$, negative attitude of classmates $(p<0.001)$, and having an illiterate caregiver $(p<0.02)$ all showed a significant association with permanent cessation of schooling. The study demonstrates significant negative impacts of epilepsy on child education.(22)

In another prospective study conducted from January 2005 to December 2005 at the pediatric epilepsy clinic of University Hospital in which parents were interviewed about the impact of epilepsy in the life of the siblings of children with epilepsy of one hundred and twenty-seven children, siblings of 78 patients with epilepsy were evaluated. From, 127 siblings of children with epilepsy, 60 were girls and 67 were boys. Age ranged from 5 to 18 years old (mean=11.7 years). After the diagnosis of epilepsy, the siblings had only negative feelings toward the disease, mostly sadness and fear(23).

Regarding the effects of drug therapy in children with epilepsy some authors point out that antiepileptic drugs decrease excessive neuronal excitability to reduce or extinguish the occurrence of seizures, but effects of this process are psychomotor slowness, attention and concentration, and memory problems leading to learning and other impairments in academic functioning.(24)

In Brazil, the study by Aguiar et al. (2007) aimed to evaluate the impact of epileptic seizures in school absenteeism have shown that fifty children who participated in the study, $80 \%$ had already lost by least 
one day at school because of crisis; $46 \%$ of parents believed that the child should leave school immediately after a crisis has occurred; $60 \%$ of families allowed their children to miss school even if they did not have occurred on the respective day.(16)

Another important aspect concerns the scarce number of publications on the subject of child epilepsy and education, as well as discussions about the impact of the disease and its variables on development of these children. There were few international studies and national study that focused directly on this issue is lacking. $(16,25-28)$

The high frequency of attacks and; therefore, the greater severity of epilepsy have also been seen as a factor with a significant relationship academic performance of children with epilepsy. The negative impact of seizure frequency on intellectual performance is great resulting in low academic performance and difficulties in learning and adapting to the school environment. According with the authors, the condition may worsen when epilepsy remains active for periods of time.(29)

Regarding the organic factors related to epilepsy, some authors indicate that educational failure is related to the early onset of the disease, the frequency, and severity of epilepsy which can be mediated by a decrease cognitive. $(5,28,30)$

For Kenee et al. (2005), the early onset of epilepsy is associated with cognitive problems. The results of some studies have shown that epilepsy in the first years of life is a significant risk factor for development of problems related to intellectual functioning. $(28,31,32)$ as compared to those Longitudinal studies that show adults with epilepsy tends to have a lower educational level, higher dropout rates school and need to attend special schools or special education, resulting in higher rates of unemployment or underemployment and increased incidence of psychiatric disorders.(33-35)

Sulzbacher et al. (1999) showed that children on a monotherapy for a long time have significant cognitive impairments in relation to reading, learning, and writing. The results also showed that the drug therapy had long-term effects, because even after three years without the use of medication the children continued to present cognitive deficits.(36)

In addition, the diagnosis of epilepsy, its undesirable effects and its psychosocial connotations significantly affect personal life of the child and family. $(23,37,38)$ These authors also point out that these variables may lead to over protection behavior by parents and other family members, leading to lower academic achievement, commitment to activities daily life and independence, as well as difficulties in relating to friends within and outside the school environment, regardless of cognitive level.

Additionally, it is observed that such characteristics (early onset, severity, frequency of epilepsy, drug therapy and negative psychosocial connotation) may make epileptic children attending special schools or using special education services, although studies addressing this issue are scarce. $(39,40)$

The prevalence of the use of special education services by children with epilepsy and frequency of epilepsy 30 times higher in patients with children attending special schools or special classes within 
schools than regular school students.(27)

Berg et al. (2005) verified through a longitudinal study, which followed 613 children over five years after being that $525(85 \%)$ children were in school and that of these $315(60 \%)$ had already used some service related to special education as classes regular schools or resource rooms or attended special.(26)

In a recent study aimed to assess and understand the social and the demographic determinants of knowledge, attitude, and practice of teachers towards people with epilepsy in Addis Ababa, Ethiopia which involved 820 teachers showed ninety percent of the teachers knew epilepsy as a disease and the most common source of information was acquaintances with PWE (51.3 \%) and among those who had acquaintances with PWE, they had come across PWE in person (67.2\%), and had a student with epilepsy in class $(28.6 \%)$. The same researchers showed although $89.2 \%$ of the teachers would allow PWE into their class, the majority $(76.7 \%)$ of them preferred that the epilepsy be cured or controlled before attendance, accounting for 21.6 and $19.1 \%$ of the responses respectively. PWE were perceived insane more than infectious explaining 9.4 and $0.2 \%$ of the responses respectively.(41)

Of the 231 children aged between 5 and $<15$ years, school attendance habits had been recorded on $162(70 \%)$ and 92 of these were definitely attending school and 70 were definitely not. A significantly higher proportion of girls were at school compared with boys [47/71 (66\%) and 45/91 (49\%) respectively; chi2 $=17.8$ with Yates correction]. In this same study the proportion of all children attending school were significantly lower in older children (percentage attendance in age groups 5 to $<10$ to and 10 to $<15 \mathrm{yrs}$ being $60 \%$ and $52 \%$ respectively).(42)

In a community-based study in rural area of Ethiopia showed among the 139 persons with epilepsy identified, $49 \%$ were below the age of 10 years and $79 \%$ below 20 years and the ratio of males to females was 1.2 to $1.0 .(9)$

\section{Methods}

\subsection{Study Setting}

The study was conducted in Addis Ababa, Ethiopia at TASH. TASH was established in 1974. It is the Teaching Hospital of the Addis Ababa University, College of Health Sciences, and School of Medicine, located in Lideta sub-city. It is also the largest referral hospital in Ethiopia with a number of specialties and subspecialties. The hospital has totally around 600 beds and serves about 250,000 patients as outpatients annually.

The PNC is follow up clinic for an outpatient follow up of pediatric patients with neurologic problems. Most of the patients are children with seizure disorder. The clinic works half day (morning) in working days of the week. It is run by trained nurses, a general practitioner, Pediatric and Child Health Residents, and a pediatric neurologist. It is attended by children and adolescents in the age ranges of 0-18 years. The average number of patients attending the clinic on monthly basis is around 600 of which more than 
$60 \%$ are children with seizure disorder. Clinically stable patients with good seizure control are appointed to come every 2-3 months.

\subsection{Study Population}

School age children and adolescents account for the majority of the children attending the pediatrics neurology clinic. The source population for the study is school age children and adolescents aged 7-18 years, and their primary caretakers attending the PNC during study period (between April and July 2018).

\subsection{Study Design and Study Period}

The study is a facility based cross-sectional study that was conducted at the PNC in TASH between April and July 2018.

\subsection{Sample size determination}

Sample size is calculated using the EPI info statistical package for sample size and power calculation. The predicted school absenteeism among children with seizure based on Brazil study was $88 \%$ (ref). Taking an assumption of school absenteeism among children with seizure $88 \%$ to obtain a confidence level of $95 \%$ and a power of $80 \%$, a total of 162 children had to be considered. Taking an additional $20 \%$ non-responders means at least 178 children and adolescents were supposed to be recruited.

Alternate sample size calculation using formula:

$\mathrm{n}=\mathrm{Z}_{\mathrm{a} / 2}{ }^{2} \mathbf{P}(\mathbf{1}-\mathrm{P}) / \mathrm{d}^{2}$ [where: $\mathrm{n}=$ sample size, $\mathrm{Z}_{\mathrm{a} / 2}$ significance level for $95 \% \mathrm{Cl}=1.96, \mathrm{P}$ (expected proportion $)=$ taken as $88 \%(0.88), d($ margin of error $)=0.05]$

$n=162$

Taking additional 10\% non-responder caregivers, the final sample size calculated will be 183 .

\subsection{Sampling Technique}

All school aged children and adolescents with seizure disorder aged between 7 and 18 years of age attending the PNC during the study period fulfilling the inclusion criteria stated below were asked to participate in the study. Willing study subjects were included in the study until the minimum sample size was attained and more children were also recruited until the study period is finalized.

\subsection{Inclusion and Exclusion Criteria}

\section{Inclusion criteria}

- Age 7-18 years and attending school at least the past 6 months in an academic year. 
- Diagnosed with seizure disorders.

- On follow up at a neurologic clinic.

\section{Exclusion criteria}

- Not started school

- Those with physical disability who can't walk by themselves.

- Those whose parent or caretaker doesn't consent.

\subsection{Data collection}

\section{Study Questionnaire}

For study participants who fulfilled the inclusion criteria stated above, a confidential written informed consent (Annex I) form was given. A structured, pre- tested study questionnaire (Annex II) was administered to collect data on the socio- demographic characteristics, primary caregiver's information; seizure related and school related characteristics, seizure disclosure status of participant child/ adolescent/caregiver to school teachers and peers. Medical charts of all children attending follow up at PNC during the study period were reviewed to retrieve information regarding other medical illness, type of seizure, and check how well seizure is controlled. All other items on the study questionnaire were clearly discussed with data collectors before data collection is started, to enhance their awareness on the instrument.

After nurses took consent from parents/guardians, data was collected by 4 pediatric residents who were trained on recruiting and filling of the questionnaire at the PNC. The Primary investigator regularly supervised the data collection process, to assure quality and completeness of the data collected by the pediatrics resident at the clinic.

\subsection{Study variables}

\section{Independent variables}

- Socio-demographic data - Age, sex, address, residence, religion, family size, child's level of education and school performance, primary caregiver's relation with study participant, primary caregiver's level of education and income were collected.

- Seizure related data - age at seizure onset, duration, seizure type, seizure frequency, and therapy.

- Parental or primary caregivers' disclosure status of epilepsy to the teachers or peers.

\section{Dependent variables}

- School absenteeism 


\subsection{Data Quality Assurance}

As stated above, during the time of data collection, regular supervisions was made by the primary investigator in the data collection procedures. Timely feedbacks were given to data collectors to maintain data quality.

\subsection{Data analysis and Interpretation}

After data cleaning and entry, analysis was done using the Statistical Package for Social Sciences (SPSS) version 22. Variables will be defined, categorized and recoded. Descriptive statistics is used to summarize the data. Mean (standard deviation) or median (range) was used to summarize continuous variables, while frequency and percentage was used to summarize categorical variables. Binary logistic regression analysis was used to determine the associations between independent variables with the dependent variable one by one. Variables which showed significant association with school attendance in binary logistic analysis were included at once in logistic regression analysis to calculated adjusted odds ratios with the $95 \%$ confidence interval. For all statistical analysis a $p$ value of $<0.05$ is considered statistically significant.

\subsection{Operational definitions}

- School-age children: defined as those children with the cognitive skills and emotional maturity of normally developing child of age 7-12 years.

- Seizure: a transient occurrence of signs and/or symptoms due to abnormal excessive or synchronous neuronal activity in the brain.(1)

- Epilepsy: Clinical diagnosis of epilepsy usually requires the occurrence of at least 1 unprovoked epileptic seizure with either a second such seizure or enough EEG and clinical information to convincingly demonstrate an enduring predisposition to develop recurrences.(1)

- Symptomatic seizure: defined as seizure/epilepsy that follows an injury(head injury, CNS infection, stroke, brain tumor, and surgery) to the brain known to be capable of causing epilepsy.(1)

- Complete seizure control: Defined as complete remission of seizure for six months or more.(43)

- Partial seizure control: Defined as more than fifty percent reduction of frequency of seizure.(43)

- Poor seizure control: One or more seizure per month over period of 6 months or more and who had experienced trials of at least two different AEDs at optimum doses alone or in combination with adequate compliance.(43)

\section{Results}

\subsection{Socio-demographic findings}


This study included 183 children with epilepsy, more than half (55.7\%) of these patients were male. and the majority $(72.7 \%)$ of these children were in the age group of 7 to 12 years (Table 1 ).

As presented in Table 1, majority of the study participants 118(64.5\%) reside in Addis Ababa and about 44(24.0\%) were from Oromia region. Regarding the birth order 82(44.8) were first, $42(23.0 \%)$ second, $26(14.2 \%)$ third and the remaining $33(18.0 \%)$ were above third birth order.

The mean family size was 4.8 and $94(53.7 \%)$ had family sizes of five or more members. Two hundred twenty three $(67.2 \%)$ of the children with epilepsy attended primary schools. Some, 56 (30.6\%) were attending below primary school which is not age appropriate, while $84(45.9 \%)$ repeated grades.

Selected socio-demographic characteristics of primary caregivers are presented in Table 2. Mothers were primary care givers for $71(38.8 \%)$ study participants. Study participants who were raised by single fathers and both parents accounted for $34(18.6 \%)$ and $68(37.2 \%)$ respectively. The majority of the primary caregivers are currently married (80.9\%).

One hundred twelve (61.9\%) of the primary caregivers completed secondary school education and more. Only 140 (76.5\%) of the care givers disclosed their income, among whom only $75(53.6 \%)$ earned $>1500$ Birr/month and one hundred nineteen (65\%) of primary caregiver perceived the income to be inadequate.

\subsection{Seizure characteristics}

The mean age at onset of seizure was 4.6 years while the median age at onset of seizure being 5.0 years and $36(19.7 \%)$ of them have onset during infancy period. On the other hand the mean and median of duration of seizure were 5.7 and 5.0 years respectively and in 113(61.7\%) of them had seizure 5 year and more. When we see the seizure type in figure 1 majority of patients $132(72.1 \%)$ have generalized onset, $49(26.8 \%)$ have focal onset type and the remaining $2(1.1 \%)$ have unclassified seizure type.

When we see the frequency of seizure in figure 2 most patients $104(56.8 \%)$ had less than or equal to one seizure episode per month and the remaining $79(43.2 \%)$ had more than one seizure per month. Regarding treatment given most patients $130(71.4 \%)$ got mono-therapy and others $46(25.3)$ got poly-therapy as seen in figure 3.

Of the total 183 study subjects About $44(24.0 \%$ ) had symptomatic seizure; (figure 4 ) on the other hand the rest $139(76.0 \%)$ do not have symptomatic seizure. When we see level of seizure control; complete control was observed in 92(50.3\%), partial control in 57(31.1\%), poor control in 33(18.1\%) and not documented in one patients (figure 5).

Regarding impact of seizure on school absenteeism 127(69.4\%) children miss school days because of the seizure effect and most(90) of them miss between 1 to 10 days(Table.4\& figure.6) and only 4 ceased there school during this year. The mean number of missed school days is 12.6 days; the range being between 1 and 120 missed school days in the last 6 months. 
There are several reasons mentioned by Primary care givers of those who missed school days why their children miss school days. Majority students $102(80.3 \%)$ miss school days for medical appointment, $64(50.4 \%)$ children miss school days because of having seizure before school and the remaining $27(121.3 \%)$ miss school because of having seizure at school (Figure 7 ).

From the study participants $88(48.1 \%)$ of them had seizure at school from which $81(92 \%)$ of them went home immediately while the rest seven stayed at school after feeling better.

Teachers had expressed apprehension to the primary care giver regarding the diagnosis of epilepsy only in $71(38.2 \%)$ of the cases. The teachers are mainly concerned because they fear that other students could be disturbed and the school performance of affected children may decline.

The teacher informed the caregivers that the children with epilepsy should stay at home in $17 \%$ of the cases. On the other hand the primary care givers claimed that they allowed $19.2 \%$ of their children to miss school days even when there is no illness. The main reason the parents mentioned is fear that children might have seizure at school in $75 \%$ of cases.

Binary logistic regression analysis was used to assess the association between selected background covariates independent variables (Socio demographic variables, seizure related variables and schooling variables) against dependent variable (school absenteeism) of study participants is shown in Table $\mathbf{5}$.

The results of binary logistic regression analysis of relevant predictors on absenteeism individually, shows that among the factors tested the older age group, female sex, duration of seizure $\geq 5$, status of repeating grades, having seizure at school, having frequent seizures and having seizures for longer duration or disclosing seizure to teachers, were associated with school absenteeism.

Logistic regression analysis including all the above stated factors which are significantly associated with school absenteeism was run to calculate adjusted odds ratios. The results show that only female sex, having symptomatic seizure, having seizure at school or having longer duration of seizure were identified as independent determinants of poor attendance.

\section{Discussion}

In an endeavor to assess the impact of seizure on school absenteeism in school age children and adolescents between the ages of 7 and 18 years who were attending follow up at the PNC in Tikur Anbessa Specialized Hospital (TASH), 183 children with epilepsy were recruited. To our knowledge this study is the first of its kind in Ethiopia which is set to determine the prevalence of epilepsy among school aged children and to identify factors affecting school attendance among children with epilepsy. In order to design future interventions to improve school attendance, identifying the factors affecting school absenteeism in children with epilepsy is very important

From our study the prevalence of school absenteeism among children aged 7-18 years at PNC follow up were $69.4 \%$. The prevalence of poor attendance is lesser in our study than reported in a research done in 
the Brazil (88\%) but higher than in reported by a study conducted in Sera lion (50\%) and a study by CDC $(36 \%)(16,20,22)$. The differences in estimated prevalence of poor school attendance could be attributed to the difference in sample size used, the demographic characteristics, seizure duration, and the varying definition of poor attendance.

More children with epilepsy within the age group of $13-18$ years (82\%) missed school. The higher proportion of absenteeism in this age group may reflect the difficulty of coping with epilepsy among older children due to possible longer duration of the disease since onset and fear of dealing with the stigma associated with the illness.

Similar to the other studies, our findings show that the major reason for missed school days was due to seizure $(20,22)$. Totally four children $(3.2 \%)$ ceased attending school in our study is fewer than reported in a study done in Serra lion which was about $20 \%$. Education is very important for all children and especially for children with epilepsy as it could facilitate adaptive functionality and better integration in the society. Therefore cessation of education should not an option in children with epilepsy rather allowing children to come to clinic after school after medical appointments and improved seizure control might help children decrease absenteeism.

The proportion of the two sexes in our study was similar to the proportion reported in a study that determined the incidence of epilepsy in rural central Ethiopia (9). In this study, there were statistically significant association between female sex and missed school days. More female (79\%) than male (63\%) children with epilepsy missed school days. Female children with epilepsy were 2.2 times more likely to miss school days than their male counterparts. In developing countries like Ethiopia where enrollment and retention of female children at school is poor, this result is expected. In addition female children with epilepsy are at increased risk of developing depression due to the illness which could perhaps affect school attendance negatively. Our finding, however, contradicts the finding of a study that showed higher proportion of school attendance among female than male children (42). The finding of this study shows the need to reach out for female children with epilepsy even more than the male children. Stronger social support to boost the confidence and better function of children with epilepsy are required.

More number of care givers has disclosed the condition of the children to the teachers (86.9\%). As teachers could support children with epilepsy, it is encouraging to know that most of the careers willingly disclose the status of the children to their teachers. Unfortunately, more number of the children whose status is known by the teachers missed school day as opposed to children whose status was not disclosed to their teacher. The preference of the teachers to let the children stay at home till their seizure is cured before coming to school can be the reason for poor attendance (41). Therefore it is important to equip teachers with the knowledge and resources required to handle children with epilepsy to avoid more number of missing days. Furthermore, teachers and care takers could plan ways to make up for missed days of school to improve attendance of the children.

Having symptomatic seizure and longer duration of seizure identified as the independent determinants of missing school. This could be associated with the illness and potential fear of stigma associated with 
having the illness. Children who experienced seizure at school are less likely to miss school than those who never had seizure at school. This could perhaps be due to a good collaboration of the care takers and teachers in reassuring the children with seizure.

Greater proportions of the primary caregivers of the children were married $(80.9 \%)$ and more than half of had attended high school or higher education (59.6\%) and have a secured monthly income (68.2\%). These characteristics of careers are expected to affect school attendance of children with epilepsy positively. Though, more proportion of children raised by parents of lower education level missed school than those raised by parents of higher education level, our findings fail to demonstrate a statistically significant association between family size, marital status of parents, socioeconomic status and educational status of parent's with school absenteeism.

As shown in our results despite the absence of any illness the parents allowed $19.2 \%$ of their children to miss school days. Excessive fear and concerns of care takers of children with epilepsy need to be tackled through reassurance and education to improve school attendance.

In this study, though not statistically significant, children with more than one seizure per month have missed school more than those who had less frequent seizure but other studies suggest the negative impact of seizure frequency on intellectual performance resulting in low academic performance and difficulty in learning (29). Direct effect of seizure on wellness of the children and its indirect effect on cognition may both result in poor attendance among children with epilepsy $(5,28,29$, and 30$)$.

More children who repeated grade $(78.6 \%)$ missed more school days than those who never repeated their grade $(61.6 \%)$. There is a statistically significant association between repeating grade and poor attendance. A possible inference from this is that repeating a grade could negatively affect school attendance. Children with epilepsy are likely to have associated learning difficulties, therefore each child learning abilities need to be assessed before commencement and during the learning process. Therefore, the schools need to identify trained personnel who could identify learning challenges of the child and who could suggest potential measures to be taken to improve progress of learning of the children with epilepsy to avoid repeating classes.

\section{Limitations of the study}

This study tried to highlight the impact of seizure on school absenteeism among school aged children. Nevertheless, it should be noted that the study has the following limitations.

- First, the study was conducted in one tertiary hospital, which could result in an under or over estimation of the actual burden of the problem on the society as a whole and our questioner were not validated questioner.

- Second, the absence of comparison group (control group) in the study makes it difficult to make definite conclusions. 
- Third, though this study clearly showed the impact of seizure on school absenteeism it doesn't show the effect of school absenteeism on school performance.

- Finally, income disclosure among caregivers of the study participants was limited for use as a covariate in further statistical analysis.

\section{Conclusion}

This study demonstrated the school absenteeism is very common among children aged 7-18 years at PNC follow up (69.4\%). Furthermore, female sexes, seizure duration, symptomatic are significantly associated with school absenteeism. Based on the findings identified by the current study it could be possible to conclude that seizure has a significant impact on children's school attendance. Therefore there is a need for collaborative action by clinicians, teachers, care takers and school administration to improve attendance.

\section{Recommendations}

1. It is important that TASH should involve the primary care takers and facilitate a regular neuropsychological assessment and continuous follow up and care in its Neurologic clinic or in any of its clustered health facilities for children and adolescents.

2. In order to curb increased rate of absenteeism, female children and adolescents having a longer duration of active epilepsy, longer duration of seizure and who previously repeated grade should be targeted

3. To reduce apprehension, training of the teachers and care takers on how to deal with these special groups of children and their mental health issues is important.

4. The importance of improving attendance and performance at school for better integration of the children in the society need to be communicated to the careers and the teachers.

5. Allowing children to come to clinic after school after medical appointments and improved seizure control might help children decrease absenteeism.

6. Special support group should be established in schools which cater for the needs and limitations of children with epilepsy are needed to improve school enrolment, attendance and retention of children with epilepsy.

7. Documented seizure action plans individualized to each student with seizure must be available at the school.

8. Further population-based studies to determine other reasons of school absenteeism among children with epilepsy need to be conducted.

\section{Abbreviations}

ADHD Attention Deficit Hyperactivity Disorder 


$\begin{array}{ll}\text { AOR } & \text { Adjusted Odds Ratio } \\ \mathrm{Cl} & \text { Confidence Interval } \\ \text { CWE } & \text { Children with Epilepsy } \\ \text { CNS } & \text { Central Nervous System } \\ \text { CSHCN } & \text { Children with Special Health Care Needs } \\ \text { EEG } & \text { Electroencephalography } \\ \text { FMoH } & \text { Federal Ministry of Health } \\ \text { ILAE } & \text { International League against Epilepsy } \\ \text { OR } & \text { Odds Ratio } \\ \text { MDG } & \text { Millennium Development Goals } \\ \text { NCDs } & \text { Non-Communicable Diseases } \\ \text { PNC } & \text { Paediatric Neurology Clinic } \\ \text { SPSS } & \text { Statistical Package for Social Sciences } \\ \text { TASH } & \text { Tikur Anbessa Specialized Hospital } \\ \text { WHO } & \text { World Health Organization }\end{array}$

SSNPR Southern Nations, Nationalities, and Peoples' Region

\section{Declarations}

\section{Ethical approval and consent to participate:}

Ethical clearance was obtained from the Department of Pediatrics and Child Health Research and Publications Committee of the School of Medicine, College of Health Sciences, Addis Ababa University.

\section{Consent for publication:}

Not required.

\section{Availability of data and material}

The datasets generated or analyzed during the current study are not publicly available due to intuitional policy but are available from corresponding author on reasonable request. 


\section{competing interests}

The authors declare that they have no competing interests.

\section{Funding}

No funding was obtained for this study.

\section{Authors' contributions}

$\mathrm{OH}$ was responsible for overall conceptualization, writing most of the article and conduct of the study.

AM was a pediatric neurologist who contributed toward modifications and finalizing the article.

\section{Acknowledgements}

I would like to acknowledge the staff members at the pediatric neurology clinic who helped me with the data collection. This study would not have materialized without the primary caregivers of the children and adolescents at the PNC who consented to participate. Last, but not least, I am very grateful for the encouragement and support provided by my wife and other close family members.

\section{References}

1. Kliegman RM, Behrman RE, Jenson HB, Stanton BM. Nelson textbook of pediatrics (Edition 20.). Phialdelphia, PA: Elsevier: Elsevier Health Sciences; 2016.

2. Ettinger AB, Weisbrot DM, Nolan EE, Gadow KD, Vitale SA, Andriola MR, et al. Symptoms of depression and anxiety in pediatric epilepsy patients. Epilepsia. 1998;39(6):595-9.

3. Arroyo HA, De Rosa S, Ruggieri V, de Dávila MT, Fejerman N. Epilepsy, occipital calcifications, and oligosymptomatic celiac disease in childhood. Journal of child neurology. 2002;17(11):800-6.

4. Tellez-Zenteno JF, Patten SB, Jetté N, Williams J, Wiebe S. Psychiatric comorbidity in epilepsy: a population-based analysis. Epilepsia. 2007;48(12):2336-44.

5. Aldenkamp AP, Weber B, Overweg-Plandsoen WC, Reijs R, van Mil S. Educational underachievement in children with epilepsy: a model to predict the effects of epilepsy on educational achievement. Journal of Child Neurology. 2005;20(3):175-80.

6. Izuora G, Iloeje S. A review of neurological disorders seen at the paediatric neurology clinic of the university of Nigeria teaching hospital, Enugu. Annals of tropical paediatrics. 1989;9(4):185-9.

7. Scott RA, Lhatoo SD, Sander JW. The treatment of epilepsy in developing countries: where do we go from here? Bulletin of the World Health Organization. 2001;79(4):344-51.

8. Moges A, Gizae S, Zenebe G, Kotagal S. PATTERN OF NEUROLOGICAL DISORDERS AT PEDIATRIC OUTPATIENT NEUROLOGIC SER-VICES AT TIKUR ANBESSA SPECIALIZED HOSPITAL. 
9. Tekle-Haimanot R, Forsgren L, Ekstedt J. Incidence of epilepsy in rural central Ethiopia. Epilepsia. 1997;38(5):541-6.

10. Senanayake N, Román GC. Epidemiology of epilepsy in developing countries. Bulletin of the World Health Organization. 1993;71(2):247.

11. Roman G, Sotelo J, Del Brutto O, Flisser A, Dumas M, Wadia N, et al. A proposal to declare neurocysticercosis an international reportable disease. Bulletin of the world Health Organization. 2000;78(3):399-406.

12. Brown RT, Buchanan I, Doepke K, Eckman JR, Baldwin K, Goonan B, et al. Cognitive and academic functioning in children with sickle-cell disease. Journal of Clinical Child Psychology. 1993;22(2):20718.

13. Seidenberg M, Beck N, Geisser M, O'Leary DS, Giordani B, Berent S, et al. Neuropsychological correlates of academic achievement of children with epilepsy. Journal of Epilepsy. 1988;1(1):23-9.

14. Marshall R, Cupoli J. Epilepsy and education: the pediatrician's expanding role. Advances in pediatrics. 1986;33:159-80.

15. Stores G, Hart J, Piran N. Inattentiveness in schoolchildren with epilepsy. Epilepsia. 1978;19(2):16975.

16. Aguiar BV, Guerreiro MM, McBrian D, Montenegro MA. Seizure impact on the school attendance in children with epilepsy. Seizure. 2007;16(8):698-702.

17. Reilly C, Ballantine R. Epilepsy in school-aged children: more than just seizures? Support for Learning. 2011;26(4):144-51.

18. Wodrich DL, Cunningham MM. School-based tertiary and targeted interventions for students with chronic medical conditions: Examples from type 1 diabetes mellitus and epilepsy. Psychology in the Schools. 2008;45(1):52-62.

19. Holdsworth L, Whitmore K. A study of children with epilepsy attending ordinary schools. I: their seizure patterns, progress and behaviour in school. Dev Med Child Neurol. 1974;16(6):746-58.

20. Pastor PN, Reuben CA, Kobau R, Helmers SL, Lukacs S. Functional difficulties and school limitations of children with epilepsy: findings from the 2009-2010 National Survey of Children with Special Health Care Needs. Disability and health journal. 2015;8(2):231-9.

21. Rossi MA. Improving patient-centered care coordination for children with epilepsy: version 2.0 upgrade required. Epilepsy currents. 2014;14(3):145-6.

22. Ali DB, Tomek M, Lisk DR. The effects of epilepsy on child education in Sierra Leone. Epilepsy \& Behavior. 2014;37:236-40.

23. Tsuchie SY, Guerreiro MM, Chuang E, Baccin CE, Montenegro MA. What about us?: Siblings of children with epilepsy. Seizure-European Journal of Epilepsy. 2006;15(8):610-4.

24. Meador KJ, Loring D, Vahle V, Ray PG, Werz M, Fessler A, et al. Cognitive and behavioral effects of lamotrigine and topiramate in healthy volunteers. Neurology. 2005;64(12):2108-14. 
25. El Sabbagh S, Soria C, Escolano S, Bulteau C, Dellatolas G. Impact of epilepsy characteristics and behavioral problems on school placement in children. Epilepsy \& Behavior. 2006;9(4):573-8.

26. Berg AT, Smith SN, Frobish D, Levy SR, Testa FM, Beckerman B, et al. Special education needs of children with newly diagnosed epilepsy. Developmental medicine and child neurology. 2005;47(11):749-53.

27. Tidman L, Saravanan K, Gibbs J. Epilepsy in mainstream and special educational primary school settings. Seizure-European Journal of Epilepsy. 2003;12(1):47-51.

28. Bulteau C, Jambaque I, Viguier D, Kieffer V, Dellatolas G, Dulac O. Epileptic syndromes, cognitive assessment and school placement: a study of 251 children. Developmental medicine and child neurology. 2000;42(5):319-27.

29. Bjørnæs H, Stabell K, Henriksen O, Løyning Y. The effects of refractory epilepsy on intellectual functioning in children and adults. A longitudinal study. Seizure. 2001;10(4):250-9.

30. Mitchell WG, Scheier LM, Baker SA. Psychosocial, behavioral, and medical outcomes in children with epilepsy: a developmental risk factor model using longitudinal data. Pediatrics. 1994;94(4):471-7.

31. Nolan MA, Redoblado MA, Lah S, Sabaz M, Lawson JA, Cunningham AM, et al. Intelligence in childhood epilepsy syndromes. Epilepsy research. 2003;53(1-2):139-50.

32. van Mil SG, Reijs RP, van Hall MH, Aldenkamp AP. Neuropsychological profile of children with cryptogenic localization related epilepsy. Child Neuropsychology. 2008;14(4):291-302.

33. Jalava M, Sillanpaa M. Physical Activity, Heath-Related Fitness, and Health Experience in Adults with Childhood-Onset Epilepsy: A Controlled Study. Epilepsia. 1997;38(4):424-9.

34. Jalava M, Sillanpää M, Camfield C, Camfield P. Social adjustment and competence 35 years after onset of childhood epilepsy: a prospective controlled study. Epilepsia. 1997;38(6):708-15.

35. Sillanpää M, Jalava M, Kaleva O, Shinnar S. Long-term prognosis of seizures with onset in childhood. New England Journal of Medicine. 1998;338(24):1715-22.

36. Sulzbacher S, Farwell JR, Temkin N, Lu AS, Hirtz DG. Late cognitive effects of early treatment with phenobarbital. Clinical pediatrics. 1999;38(7):387-94.

37. Sillanpää M, Cross JH. The psychosocial impact of epilepsy in childhood. Epilepsy \& Behavior. 2009;15(2):S5-S10.

38. Camfield C, Breau L, Camfield P. Impact of pediatric epilepsy on the family: a new scale for clinical and research use. Epilepsia. 2001;42(1):104-12.

39. Serdari A, Tsalkidis A, Tripsianis G, Vadikolias K, Chatzimichael A, Piperidou C, et al. Epilepsy impact on aspects of school life of children from different cultural populations in Thrace, Greece. Epilepsy \& Behavior. 2009;15(3):344-50.

40. Völkl-Kernstock S, Bauch-Prater S, Ponocny-Seliger E, Feucht M. Speech and school performance in children with benign partial epilepsy with centro-temporal spikes (BCECTS). Seizure-European Journal of Epilepsy. 2009;18(5):320-6. 
41. Gebrewold MA, Enquselassie F, Teklehaimanot R, Gugssa SA. Ethiopian teachers: their knowledge, attitude and practice towards epilepsy. BMC neurology. 2016;16(1):167.

42. Duggan M. Epilepsy and its effects on children and families in rural Uganda. African health sciences. 2013;13(3):613-23.

43. Holmes GL, Engel J. Predicting medical intractability of epilepsy in children How certain can we be? Neurology. 2001;56(11):1430-1.

\section{Tables}

Table 1. Socio demographic characteristics of school age children and adolescents with seizure disorder attending follow up at PNC in TASH between April and July, 2018 


\begin{tabular}{|c|c|c|}
\hline $\begin{array}{l}\text { Variables } \\
\text { Age groups }\end{array}$ & Frequency & Percentage \\
\hline $7-12$ & 133 & 72.7 \\
\hline $13-18$ & 50 & 27.3 \\
\hline \multicolumn{3}{|l|}{$\begin{array}{l}\text { Mean/ } \pm \text { SD }=10.47 / 2.9 \\
\text { Sex }\end{array}$} \\
\hline Male & 102 & 55.7 \\
\hline $\begin{array}{l}\text { Female } \\
\text { Birth order }\end{array}$ & 81 & 44.3 \\
\hline First & 82 & 44.8 \\
\hline Second & 42 & 23.0 \\
\hline Third & 26 & 14.3 \\
\hline $\begin{array}{l}\text { Greater than } 3 \\
\text { Family size }(n=175)\end{array}$ & 33 & 18 \\
\hline$<5$ & 81 & 46.3 \\
\hline$\geq 5$ & 94 & 53.7 \\
\hline \multicolumn{3}{|l|}{$\begin{array}{l}\text { Mean } / \pm S D=4.85 / 1.8 \\
\text { Address }\end{array}$} \\
\hline Addis Ababa & 118 & 64.5 \\
\hline Oromia & 44 & 24.0 \\
\hline Amhara & 8 & 4.4 \\
\hline SSNPR & 10 & 5.5 \\
\hline $\begin{array}{l}\text { Other } \\
\text { Address }\end{array}$ & 3 & 1.6 \\
\hline Addis Ababa & 118 & 64.5 \\
\hline $\begin{array}{l}\text { Out of Addis Ababa } \\
\text { Religion }\end{array}$ & 65 & 35.5 \\
\hline Orthodox & 113 & 61.7 \\
\hline Muslim & 47 & 25.7 \\
\hline Protestant & 21 & 11.5 \\
\hline $\begin{array}{l}\text { Other } \\
\text { Childs level of education }\end{array}$ & 2 & 1.1 \\
\hline Nursery & 56 & 30.6 \\
\hline Primary school & 123 & 67.2 \\
\hline
\end{tabular}


Secondary school

Repeated grade

Never repeated

Repeated
4

99

84
2.2

54.1

45.9

Table 2. Socio demographic characteristics of primary caregivers of school age children and adolescents with seizure disorder attending follow up at PNC in TASH between April and July, 2018 


\begin{tabular}{|c|c|c|}
\hline $\begin{array}{l}\text { Variables } \\
\text { Primary caregivers }\end{array}$ & Frequency & Percentage \\
\hline Mother & 71 & 38.8 \\
\hline Father & 34 & 18.6 \\
\hline Both parent & 68 & 37.2 \\
\hline Adult relative & 9 & 4.9 \\
\hline $\begin{array}{l}\text { Other } \\
\text { Marital status of parent }\end{array}$ & 1 & 0.5 \\
\hline Single & 9 & 4.9 \\
\hline Married & 148 & 80.9 \\
\hline Divorced & 15 & 8.2 \\
\hline $\begin{array}{l}\text { Widowed } \\
\text { Educational status of parents } n=181\end{array}$ & 11 & 6.0 \\
\hline Less than high school & 73 & 40.3 \\
\hline High school & 39 & 21.5 \\
\hline $\begin{array}{l}\text { Collage level and above } \\
\text { Occupational status of parents }\end{array}$ & 69 & 38.1 \\
\hline Government & 41 & 22.9 \\
\hline House wife & 36 & 20.1 \\
\hline Private work & 68 & 38.0 \\
\hline Merchant & 13 & 7.3 \\
\hline Farmer & 9 & 5.0 \\
\hline $\begin{array}{l}\text { Other } \\
\text { Monthly income }(n=140)\end{array}$ & 7 & 3.9 \\
\hline$<1500$ birr & 65 & 46.4 \\
\hline$>1500$ birr & 75 & 53.6 \\
\hline $\begin{array}{l}\text { Mean=2303 (standard deviation) } \\
\text { Income }\end{array}$ & & \\
\hline Partially adequate income & 64 & 35.0 \\
\hline Inadequate income & 119 & 65.0 \\
\hline
\end{tabular}

Table 3. Frequency distributions of seizure related information of school age children and adolescents with seizure disorder attending follow up at PNC in TASH between April and July, 2018 
Page 24/34 


\begin{tabular}{|c|c|c|}
\hline $\begin{array}{l}\text { Variables } \\
\text { Age group of seizure diagnosis }\end{array}$ & Frequency & Percentage \\
\hline$<1$ year & 36 & 19.7 \\
\hline $1-5$ year & 76 & 41.5 \\
\hline$>5$ year & 71 & 38.8 \\
\hline \multicolumn{3}{|l|}{$\begin{array}{l}\text { Mean } / \pm S D=4.6 / 3.6 \\
\text { Duration of seizure }\end{array}$} \\
\hline$<5$ & 70 & 38.3 \\
\hline$\geq 5$ & 113 & 61.7 \\
\hline \multicolumn{3}{|l|}{$\begin{array}{l}\text { Mean/ } \pm \text { SD }=5.7 / 3.5 \\
\text { Seizure type }\end{array}$} \\
\hline Focal onset & 49 & 26.8 \\
\hline Generalized onset & 132 & 72.1 \\
\hline $\begin{array}{l}\text { Unknown onset } \\
\text { Focal onset }(n=50)\end{array}$ & 2 & 1.1 \\
\hline Focal clonic & 10 & 20.0 \\
\hline Focal tonic & 5 & 8.0 \\
\hline Focal myoclonic & 7 & 14.0 \\
\hline Focal with impaired awareness & 17 & 34.0 \\
\hline $\begin{array}{l}\text { Focal to bilateral tonic clonic } \\
\text { Generalized onset }(n=161)\end{array}$ & 13 & 24.0 \\
\hline Generalized tonic clonic & 118 & 73.0 \\
\hline Generalized tonic & 4 & 2.5 \\
\hline Generalized clonic & - & - \\
\hline Generalized Myoclonic & 14 & 8.8 \\
\hline Generalized Atonic & 13 & 8.2 \\
\hline $\begin{array}{l}\text { Typical absence } \\
\text { Seizure frequency }\end{array}$ & 12 & 7.6 \\
\hline$\leq 1$ per month & 104 & 56.8 \\
\hline $\begin{array}{l}>1 \text { per month } \\
\text { Type of therapy }(n=182)\end{array}$ & 79 & 43.2 \\
\hline Monotherapy & 130 & 71.4 \\
\hline Monotherapy with side effects & 3 & 1.6 \\
\hline Polytherapy & 46 & $\begin{array}{l}25.3 \\
e 25 / 34\end{array}$ \\
\hline
\end{tabular}


Polytherapy with side effects

Symptomatic seizure

Yes

No

Seizure control

Complete seizure control

Partial seizure control

Poor seizure control

Not documented
44

139

92

57

33

1
1.6

24.0

76.0

50.3

31.1

18.0

0.5

Table 4. Frequency distributions of impact of seizure in school information of school age children and adolescents with seizure disorder attending follow up at PNC in TASH between April and July, 2018. 
Ever miss a school day because of seizure

Yes

No

56

30.6

Number of days missed $(n=127)$

$<10$ days

90

70.9

10-30 days

33

25.9

$>30$ days

4

Mean/+SD $=12.6 / 31$

IF YES $(n=127)$

Had a seizure before going to school

64

50.4

Had a seizure at school and needed to go home

27

21.3

Had a medical appointment

102

80.3

Had a test scheduled

1

0.8

Other

1

0.8

Seizure at school

Yes

88

48.1

No

95

51.9

Go home before the end of classes $(n=88)$

Yes

81

92

No

Should go home immediately

7

8

Should go home immediately 58

31.7

Can stay at school if he/she feeling well 125

68.3

Apprehension regarding the diagnosis of epilepsy

Yes

71

38.2

No

Type of apprehension $(n=69)$

110

60.8

Fear of not being able to assist the child

14

17.7

Fear of decline in school performance

27

34.2

Fear that the patient could disturb the other

Teacher suggest that the child should be kept at home because of

38

48.1 seizure

Yes

No 
Allow child to miss a day of school even if he/she in not sick

Yes

No

80.8

Reason ( $n=35)$

Fear that he/she might have a seizure at school

27

75.0

No particular reason

3

8.3

Other

6

16.7

Another son/daughter, did he/she ever have to miss a school day due to his/her brother/ sister's seizures

Yes

No

12

6.6

170

93.4

Guardians disclose epilepsy status of a child to teacher

Yes

No

159

86.9

22

13.1

Guardians disclose epilepsy status of a child to peer

Yes

105

57.4

No

78

42.6

Table 5. Bivariate logistic regression analysis of associated covariates of school absenteeism of school age children and adolescents with seizure disorder attending follow up at PNC in TASH between April and July, 2018 
Variables

Age groups

7-12 years

13-18 years
School absenteeism COR( $95 \% \mathrm{Cl})$

No (\%) Yes (\%) P value

47(35.3) $\quad 86(67.7) \quad 2.49(1.1-$

$9(18) \quad 41(82)$

5.6)

0.026 *
AOD $(95 \%$

$\mathrm{Cl})$

$P$ value

Sex

Male

39(38.2) 63(61.8)

Female

17(21.0) $\quad 64(79.0)$

$2.33(1.2-\quad 2.19(1.03-$

4.6) 4.84)

$0.013^{*}$

$0.046^{\star}$

Family size

$$
\begin{array}{lll}
24(29.6) & 57(70.4) & \\
32(31.4) & 70(68.6) & 0.89(0.45- \\
& & 1.70) \\
& & 0.440
\end{array}
$$

Duration of seizure

$<5$

$\geq 5$

Repeated grade

Never repeated

Repeated

Marital status of parent

Single, divorced and widowed parent

Married
$9(52.9) \quad 8(47.1)$

47(28.3) 119(71.7)
3.12(1.64-
6.05)
2.36(1.09-
5.15)
0.0006*

$2.01(0.83-$

0.130 
College level and above

$$
\begin{array}{lll}
12(30.8) & 27(69.2) & 1.0(0.5- \\
28(40.6) & 41(59.4) & 1.9) \\
& & 0.940 \\
& & 1.31(0.2- \\
& & 27.4) \\
& & 0.82 \\
& & \\
39(37.5) & 65(62.5) & 2.18(1.13- \\
17(21.5) & 62(78.5) &
\end{array}
$$

Seizure frequency

$=<1$ month

$>1$ month

$1.55(0.69-$

3.55)

0.299
4.19(2.1-

8.4)

0.021 *
$0.39(0.17-$

0.89)

0.024 *

Symptomatic seizure

No

Yes

Guardians disclose epilepsy status of a child to teacher

Yes
No $\begin{array}{lll}35(25.2) & 104(74.8) & 2.71(1.33- \\ & & 1.55)\end{array}$

21(47.7) 23(52.3)
2.51(1.09-

5.86)

0.038 *

13(54.2) $11(45.8)$

$\begin{array}{lll}43(27.0) & 116(73) \quad 3.19(1.33- \\ & & 7.6)\end{array}$

0.009*
0.40(0.13-

1.18)

0.097

Figures 


\section{Seizure types}

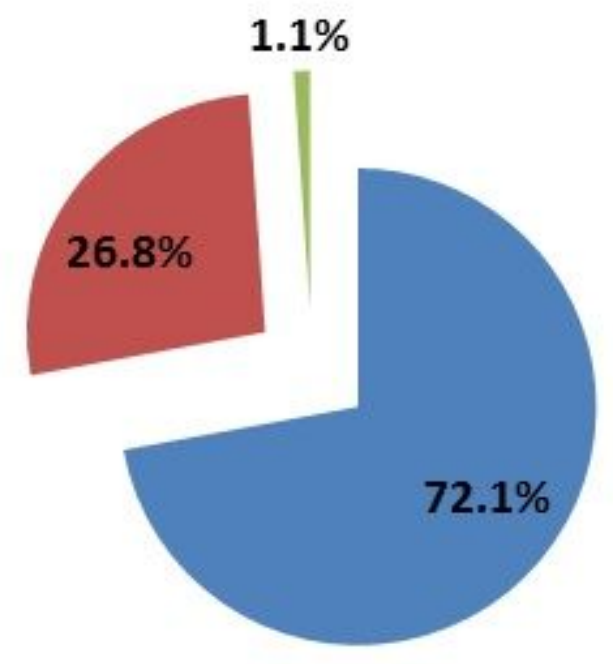

aeneralized onset

a Focal onset

- Unclassified

Figure 1

Different types of seizure

\section{Seizure frequency}

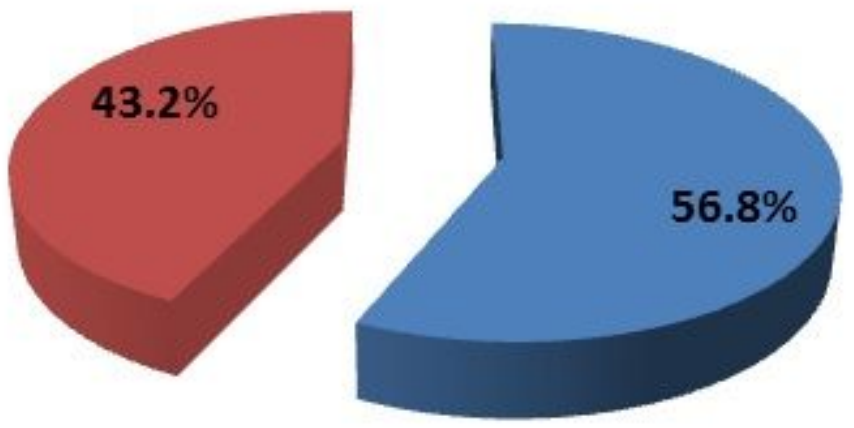

a $\leq 1$ seizure/month

n > 1seizure/month

Figure 2

Seizure frequency per month 


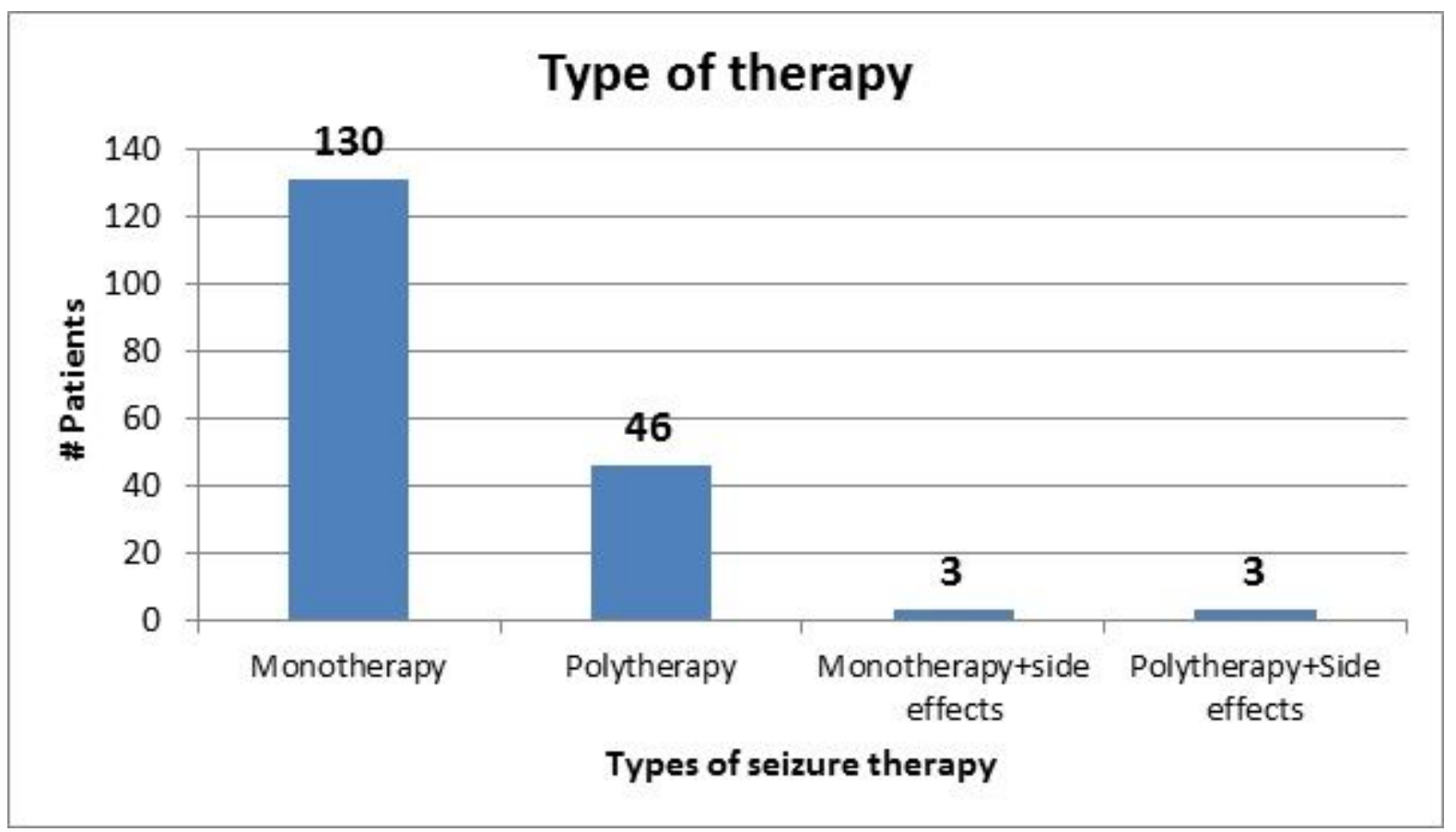

Figure 3

Different types of seizure therapy

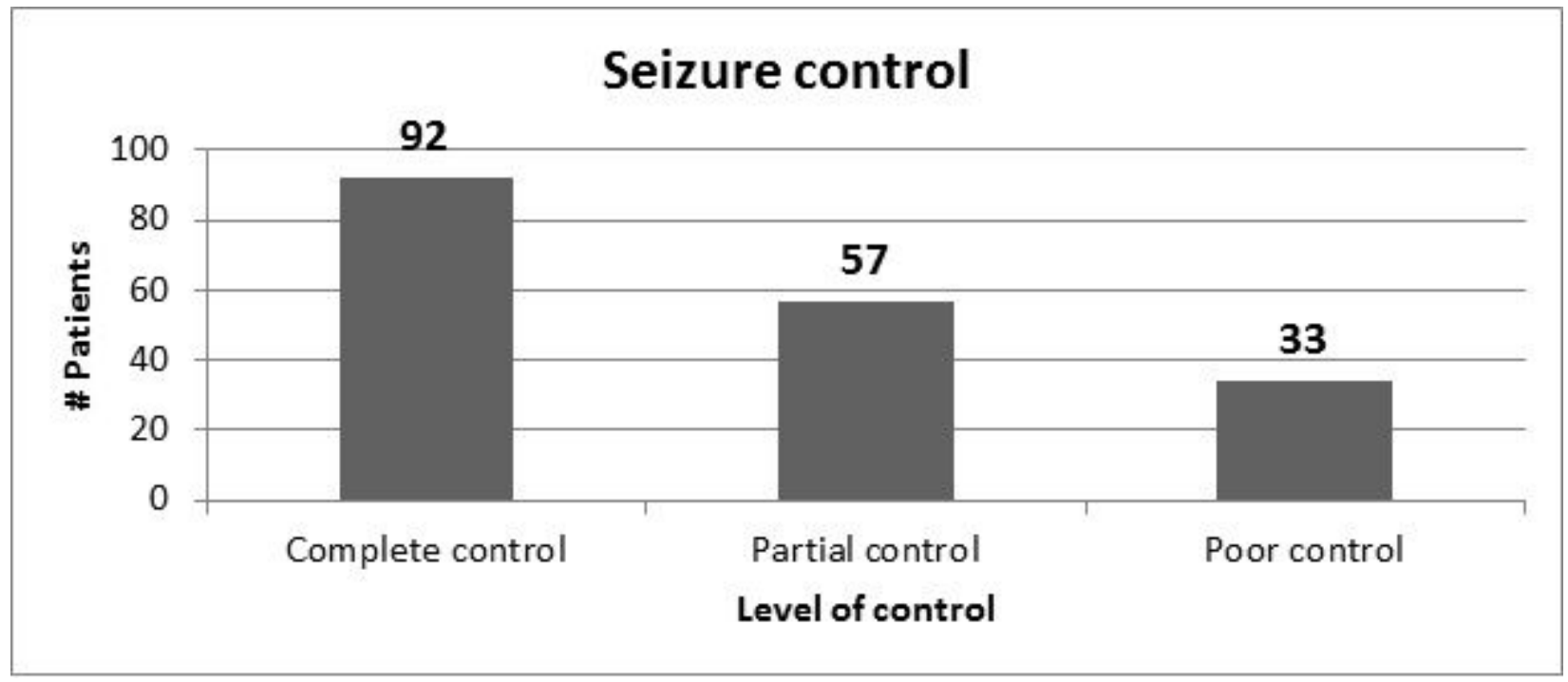

Figure 4

Level of seizure control 


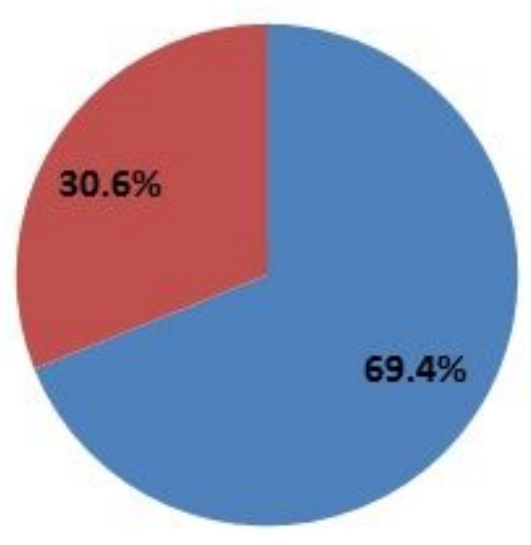

Yes No

\section{Figure 5}

Percentage of students who miss school days

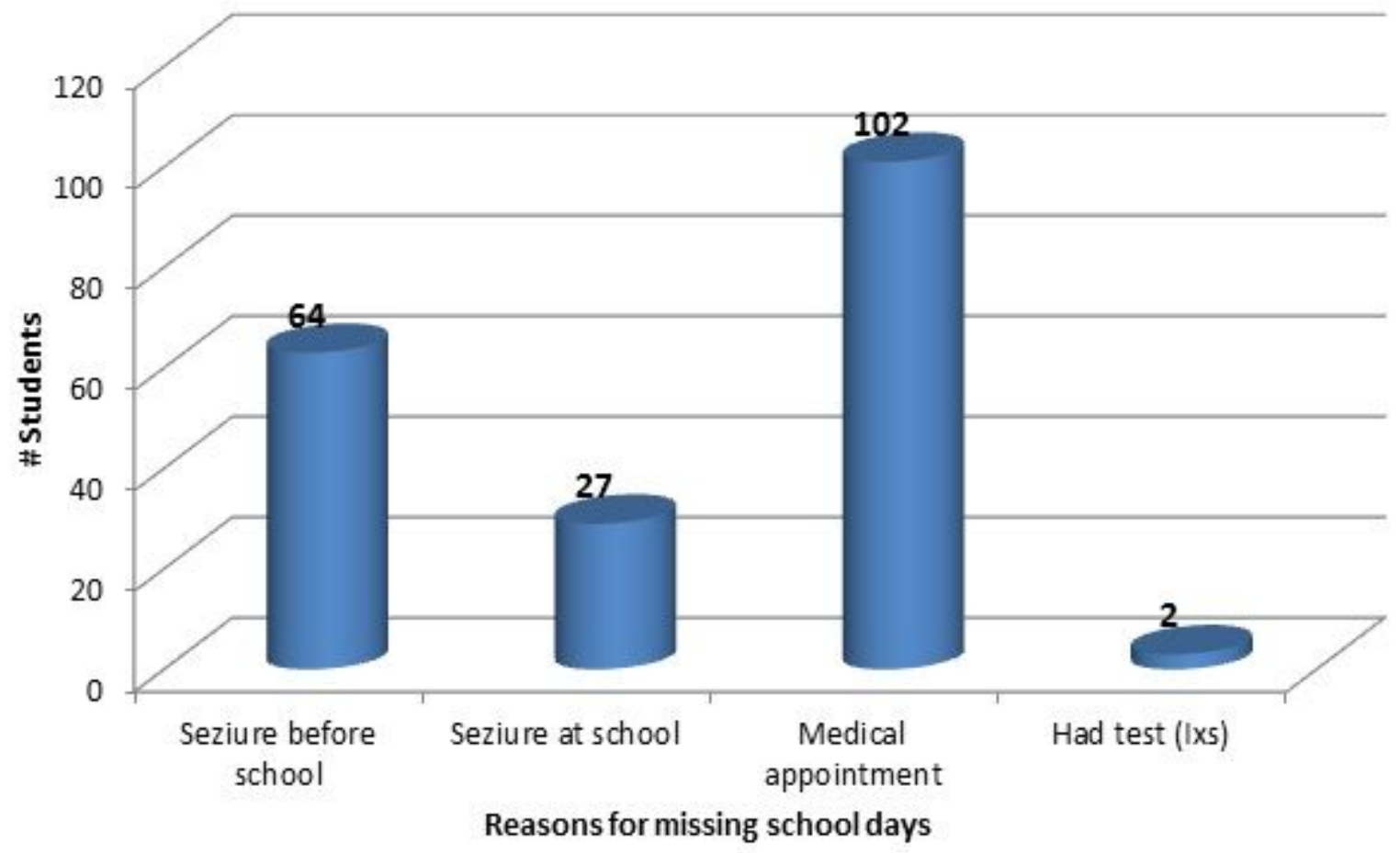

Figure 6

Reason why they miss school days

\section{Supplementary Files}


This is a list of supplementary files associated with this preprint. Click to download.

- STROBEchecklist.docx

- Annexes.pdf 